\title{
Numerical Simulation of Fracturing in Coals Using Water and Supercritical Carbon Dioxide with Potential-Based Cohesive Zone Models
}

\author{
Jianfeng Yang, Yuqing Ren, Dingding Zhang $\mathbb{D}^{\mathbb{D}}$, Yongliang Liu $\mathbb{D}^{\mathbb{D}}$, and Zhe Ma \\ Key Laboratory of Western Mine Exploitation and Hazard Prevention, Ministry of Education, Xi'an University of Science \\ and Technology, Xi'an, Shaanxi 710054, China
}

Correspondence should be addressed to Dingding Zhang; zhangdd@xust.edu.cn

Received 10 July 2021; Accepted 14 August 2021; Published 17 September 2021

Academic Editor: Haojie Lian

Copyright ( 2021 Jianfeng Yang et al. This is an open access article distributed under the Creative Commons Attribution License, which permits unrestricted use, distribution, and reproduction in any medium, provided the original work is properly cited.

\begin{abstract}
The Park-Paulino-Roesler (PPR) cohesive zone model (CZM) for coal was established for analyzing mixed-mode I/II fractures using semicircular specimens under punch-through shear (PTS) and three-point bending (SCB) tests. In these methods, the main parameters of the fracture were obtained through SCB tests and PTS tests. And according to the experimental results, the coal specimens show obvious characteristics of ductile fracture under mode I and II loading. Moreover, hydraulic and supercritical carbon dioxide $\left(\mathrm{ScCO}_{2}\right)$ fracture tests were conducted, and accordingly, it was found that the crack initiation pressure of coal specimens for hydraulic fracturing is $17.76 \mathrm{MPa}$, about 1.59 times that driven by $\mathrm{ScCO}_{2}$. And the crack initiation time of coal with $\mathrm{ScCO}_{2}$ fracturing is $123.73 \mathrm{~s}$, which is 1.58 times that for hydraulic fracturing. A macrocrack eventually formed in the coal specimen due to the hydraulic drive, which penetrated through the entire specimen. Yet, there was no crack penetrating the whole fracture specimen and several widely distributed secondary cracks in the fractured coal specimens by $\mathrm{ScCO}_{2}$. Furthermore, zero-thickness pore pressure cohesive elements were utilized to investigate multicrack propagation in coals undergoing hydraulic and $\mathrm{ScCO}_{2}$ fracturing. The constitutive relationships of the established PPR CZM were introduced into the cohesive elements. The obtained results are consistent with the hydraulic and $\mathrm{ScCO}_{2}$ fracturing experiment results for the coal specimens. This indicates that the established PPR CZMs can accurately represent the crack propagation behavior in coals for hydraulic and $\mathrm{ScCO}_{2}$ fracturing.
\end{abstract}

\section{Introduction}

As an essential type of clean energy, the exploitation of coalbed methane (CBM) is of significant importance to increase the supply of clean energy, thereby decreasing concerns about greenhouse gases and realizing safe coal mining $[1,2]$. Studies show that the low permeability of coal seams is one of the main challenges for the efficient exploitation of CBM. Generally, coal permeability in Chinese mines is less than $1 \mathrm{mD}$ [3], which is much lower than that in the United States, Australia, and other countries. In this regard, hydraulic fracturing is a widely adopted technology to improve the CBM permeability and, therefore, production by injecting a large volume of water-based fluid to create and extend fracture networks $[4,5]$. Hence, in the process of hydraulic fracturing, the crack propagation behavior in coals will have a direct influence on the effect of CBM exploitation. However, there are some drawbacks to the hydraulic fracturing technology; for example, it will cause a lot of waste and pollution of water resources, and the fracturing fluid will cause "water sensitive" and "water lock" influence on coalbed methane reservoir [6]. In order to resolve these shortcomings, numerous nonaqueous fracturing technologies have been proposed $[7,8]$, among which the supercritical carbon dioxide $\left(\mathrm{ScCO}_{2}\right)$ fracturing technology has attracted much attention [9]. $\mathrm{ScCO}_{2}$ refers to a special state of $\mathrm{CO}_{2}$ when its temperature and pressure exceed $31.1^{\circ} \mathrm{C}$ and $7.38 \mathrm{MPa}$, respectively, which has unique physical and chemical characteristics, including low viscosity, high diffusion coefficient, and high density [10]. Some researchers have conducted 
experiments on rocks with $\mathrm{ScCO}_{2}$ fracturing, and the results show that $\mathrm{ScCO}_{2}$ fracturing can produce more widely distributed and complex fracture networks in rocks than hydraulic fracturing, which can significantly increase reservoir permeability [11-13]. In addition, $\mathrm{ScCO}_{2}$ also has a good displacement effect on methane adsorbed in the coal seam, which will be beneficial to improve the yield of coalbed methane [14]. Therefore, $\mathrm{ScCO}_{2}$ fracturing technology can promote the efficient exploitation of coalbed methane, and the most important thing is the research on the crack propagation law of coal driven by $\mathrm{ScCO}_{2}$.

Since the groundbreaking work of Irwin [15] and Griffith [16], linear elastic fracture mechanics (LEFM) was established, becoming a highly effective theory framework for analyzing crack propagation in brittle solid materials. Bieniawski [17, 18] systematically introduced the LEFM into the research of crack propagation behavior in rocks, and since then, rock fracture mechanics has been widely used in rock materials. Generally, the fracture toughness $\left(K_{c}\right)$ is applied as an indicator, reflecting the crack propagation in natural materials [19-21]. Nevertheless, LEFM is mostly limited to investigating crack propagation in brittle rocks. Yet, some soft rocks, such as coal, exhibit generally ductile failure behaviors, represented by an obvious strainsoftening stage after the peak stress when the crack initiates $[22,23]$. It is because of the fracture process zone (FPZ) [24] of these soft rocks, i.e., the particular region in front of the crack tip, where a series of nonlinear softening behaviors including microcrack initiation, and plastic strain and mineral crystal friction occurrence, are sizable. It is also nonnegligible relative to the size of the rock specimen and the size of the crack. In comparison to brittle rocks, abundant primary pores and microfissures exist in the coal body [25], causing the ductile fracture characteristics of coals to be more prominent. Thus, the theory of LEFM does not apply to the study of the fracture behavior of coals.

The CZM inspired by the studies of Barenblatt [26], Dugdale [27], and Hillerborg et al. [28] has been used with success to represent the crack propagation behavior in nonlinear FPZ of ductile materials. In this theory, the FPZ is simplified hypothetically to a discrete line or plane corresponding to either a two-dimensional or three-dimensional case, respectively, in which the hypothetical cohesive stress causes the virtual crack to close (see Figure 1). The constitutive relation of CZM is represented by the relationship between the cohesive stress and relative displacement across this line or plane. The above constitutive relation is usually nonlinear and depends on the form of stress and the evolution characteristics of damage variables. When the material in this region is completely damaged, the cohesive stress will be lost, which means that a new macrocrack surface is generated. The energy consumed in this damaging process is the fracture energy of the material. Accordingly, it is concluded that the cohesive crack model can effectively characterize the ductile fracture behavior of coal.

Based on CZM, the numerical crack propagation model for hydraulic fracturing in a rock is established by the finite element method [29], extended finite element method [30], etc. However, the constitutive relationship of the softening

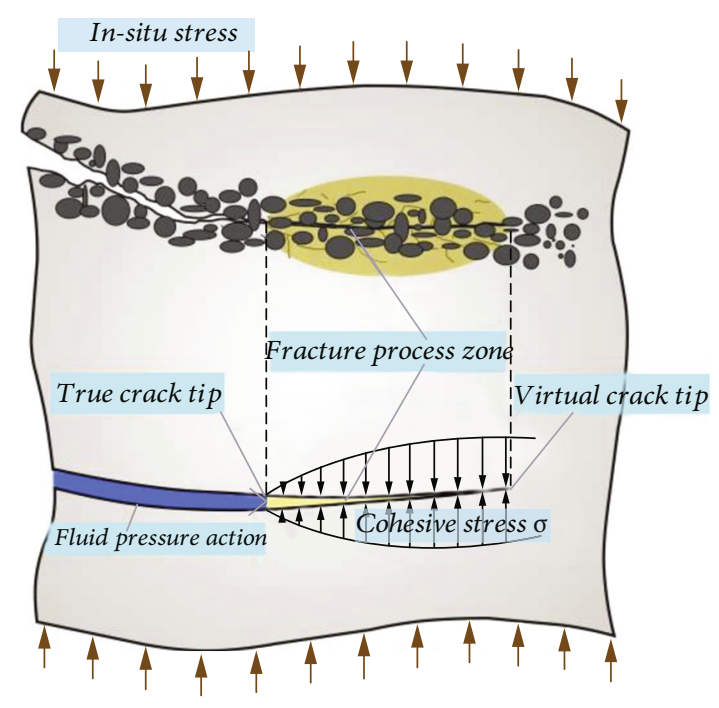

FIGURE 1: Schematic of CZM.

curve has a huge impact on fracture behaviors [31, 32], and the linear or bilinear constitutive relationships of CZMs have been adopted in previous numerical models. Hence, it is necessary to establish the CZM of coals to provide an accurate numerical model to predict crack propagation. Mixed-mode I/II crack propagation is prone to occurrence in coals under engineering conditions, especially in supercritical carbon dioxide fracturing [33]. Reviewing the literature indicates that since the LEFM method does not reflect ductile fractures, it is the most widely used scheme to investigate the crack propagation in coal $[34,35]$. On the other hand, cohesive interactions between fractured surfaces are the main failure mechanisms in the mixed-mode I/II CZM. It should be indicated that these interactions can be expressed through stress-strain equations in fractured surfaces. Nonpotential-based models [36-38] were established to characterize the ductile fracture behavior of materials. Considering symmetric systems in cohesive interactions, these models can be simply developed.

Nevertheless, the main drawback of the nonpotentialbased model is that one model cannot explain all possible separations in ductile materials. Furthermore, asymmetric tangential stiffness of material increases the computational expenses. An effective solution for this problem is to apply potential-based models to utilize the initial derivative of the fracture potential energy function [39]. This scheme is based on the cohesive stress over the fractured surfaces, while the second derivative reflects the constitutive association. Based on potential-based models, Park et al. [40] proposed the Park-Paulino-Roesler (PPR) model to simulate the cohesive fracture $[41,42]$. In this model, fracture energy (including modes I and II) and different initial slopes and cohesive strengths are considered. Meanwhile, corrective variables are defined to cover a wide range of failures in different ductile materials. This model resolves the disadvantages of traditional potential-based models.

In this work, we performed semicircular specimens under PTS and SCB tests to calculate the fracture parameters 
and establish a model of PPR for describing the mixed-mode I/II crack propagation in coals. Then, the established model is applied to perform the crack propagation simulation in hydraulic fracturing and $\mathrm{ScCO}_{2}$ fracturing in coals. Hydraulic fracturing and $\mathrm{ScCO}_{2}$ fracturing experiments were then performed for the coals. Finally, comparisons between the test results of hydraulic fracturing and $\mathrm{ScCO}_{2}$ fracturing in coals and the obtained results were utilized to evaluate the performance of the proposed model.

\section{Experimental Methods and Process}

2.1. Semicircular Specimen under SCB Test. The coal sample in this study is long-flame coal, which is taken from the Huojitu well of Daliuta Coal Mine in Shaanxi Province and buried at a depth of 97 meters. In this experiment, the semicircular specimen under the SCB experiment was used to study the mode I crack propagation behavior of coal samples and to measure the fracture parameters. As shown in Figure 2, coal samples were prepared into semidisk-like specimens, and an artificial crack was prefabricated along the symmetric center starting from the center of the bottom edge of the specimen, and vertical loads were applied on the top of the arc to cause mode I fracture of the specimen. The diameter $(2 R)$ and thickness $(B)$ of the coal rock SCB specimen were set as $70 \mathrm{~mm}$ and $25 \mathrm{~mm}$, respectively. The ratio $(\alpha / R)$ of the preset crack length to the specimen radius was set as 0.35 , and the ratio $(S / R)$ of the base supporting roller span to the specimen diameter was 0.5 . The loading mode is displacement control, and the loading speed is $0.02 \mathrm{~mm} / \mathrm{min}$. In addition, the crack tip opening displacement (CTOD) of the specimen was measured by the fiber grating (FBG) technique (with an accuracy of 0.5 microstrains) throughout the experiment. In this study, three groups of effective SCB tests were conducted on the coal specimens. In this regard, Figure 3 illustrates the loadCTOD curve of coal SCB specimens during the whole experiment, and according to the various characteristics of the experimental curve, the experimental process is generally divided into four steps, including the compaction, elastic deformation, peak load stage, and postpeak damage stages. When crack initiation occurs in coal specimens, the accumulated energy is not released instantaneously, and there is a nonlinear damage process in the postpeak loading stage. The CTOD of the three coal SCB specimens increased by $0.1192 \mathrm{~mm}, 0.1153 \mathrm{~mm}$, and $0.0895 \mathrm{~mm}$, respectively, with an average value of $0.108 \mathrm{~mm}$, from the beginning of the specimen subjected to the force to the formation of a new crack surface, that is, from the intact specimen to the fracture of the specimen.

2.2. PTS Test. This method was first proposed by Backers et al. [43] to investigate the fracture of materials in mode II loading conditions. The PTS test was used here to simulate mode II fracture experiments in coal, as it is easy to process, and the experimental results are reliable. As shown in Figure 4 , the specimen was a circular cylinder with a diameter $D$ and had circular notches with a diameter ID drilled into the upper and lower end faces along the central axis
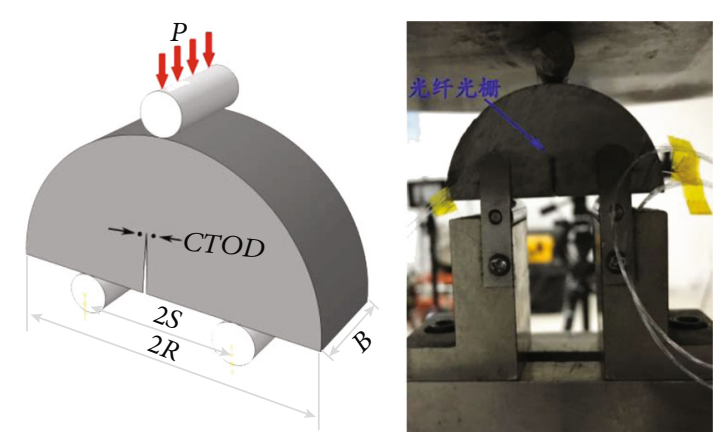

Figure 2: Coal SCB specimen [20].

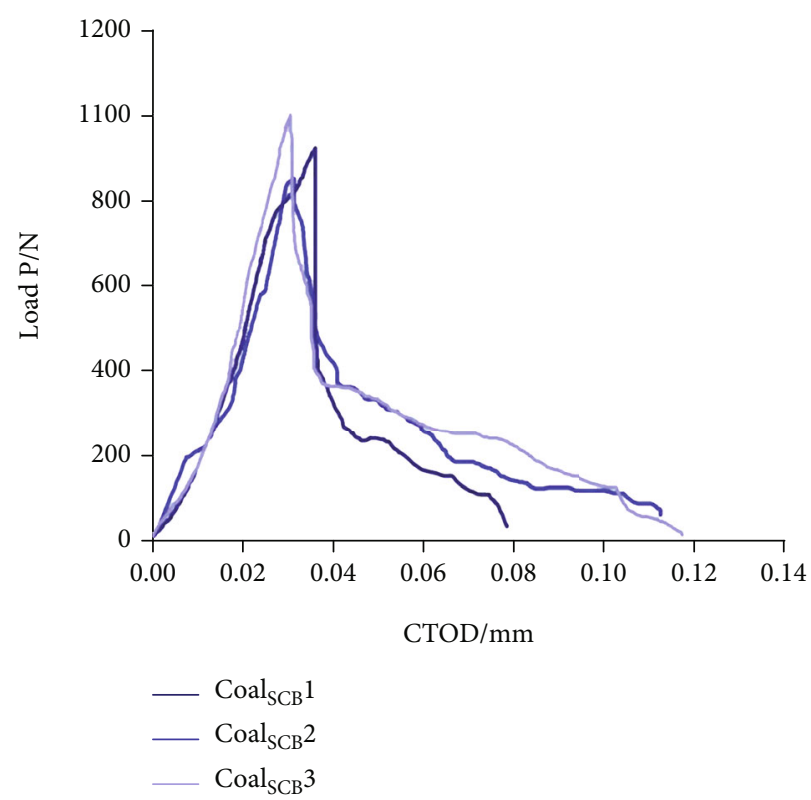

FIGURE 3: Loading-CTOD curve of coal SCB specimens.

of the cylinder. Circular cylinders with diameter $D$ and height $L$ were prepared. Moreover, two circular notches were prepared with depths $a$ and $b$ near the upper end and lower end of the specimen, respectively. The width of notches was set to $t$, and the effective shear length was $I P=L-a-b$. The experiment was performed using a loading cylinder to apply a vertical shear force $(P)$. It is found that as the applied shear stress increases, the crack propagates along the notches parallel to the axis of the cylinder, as well as mode II fracture characteristics which were then able to be acquired from the experimental results. The diameter $D$ and height $L$ of the specimens was set to $50 \mathrm{~mm}$, and the coals were cut into the PTS specimens using diamond wire cutting under the CNC machine tools. This can limit the micromechanical damage to the coal specimens and improves machining accuracy. In addition, notches with a diameter of $I D=35 \mathrm{~mm}$ were prefabricated along the same central axis utilizing a 0.5 -millimeter-thick diamond bit with the CNC machine tools. Parameters $a$ and $b$ of these notches were set to $10 \mathrm{~mm}$ and $30 \mathrm{~mm}$, respectively. Moreover, the 

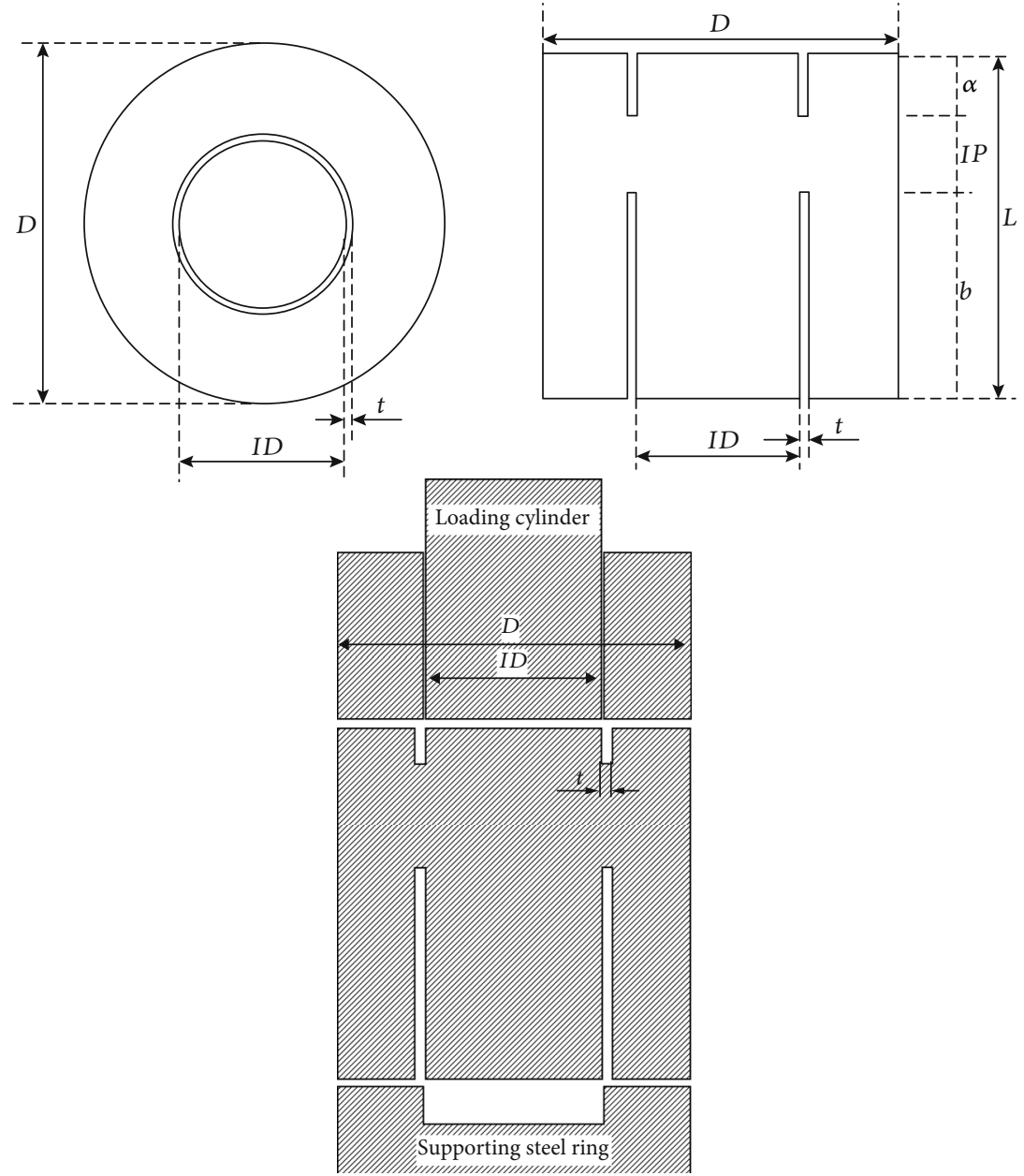

FIGURE 4: Layout of PTS specimen [43].

length of $I P$ was set to $10 \mathrm{~mm}$. Over the experiment, the specimen of coal PTS was located in advance on the bottom support, which possesses cylindrical grooves with a diameter of $35 \mathrm{~mm}$ and a depth of $15 \mathrm{~mm}$. A shear load was employed to the specimen of coal using a loading cylinder with a diameter of $35 \mathrm{~mm}$. Finally, the test was in the mode of displacement control with a constant rate of $0.02 \mathrm{~mm} / \mathrm{min}$ to ensure stable crack propagation. Three experiments were executed each for the coal. The stressstrain curves were recorded. Figure 5 shows the experimental curve of coal shear load and tangential displacement, which represents the typical coal type II fracture characteristics. In the initial stage, the shear load has a linear correlation with the shear displacement. When the critical value was obtained for the shear displacement, mode II cracks begin to occur in the FPZ of the coal sample and local damage occurs. Within the postpeak stage, the shear load progressively reduces with the enhancement of shear displacement, and the coal sample presents the characteristics of ductile fracture. The average maximum tangential displacement of the PTS coal specimen is $0.055 \mathrm{~mm}$, and the nonlinear damage softening stage appears in the postpeak stage of the shear process of the PTS coal specimen. In addition, by calculating the ratio of

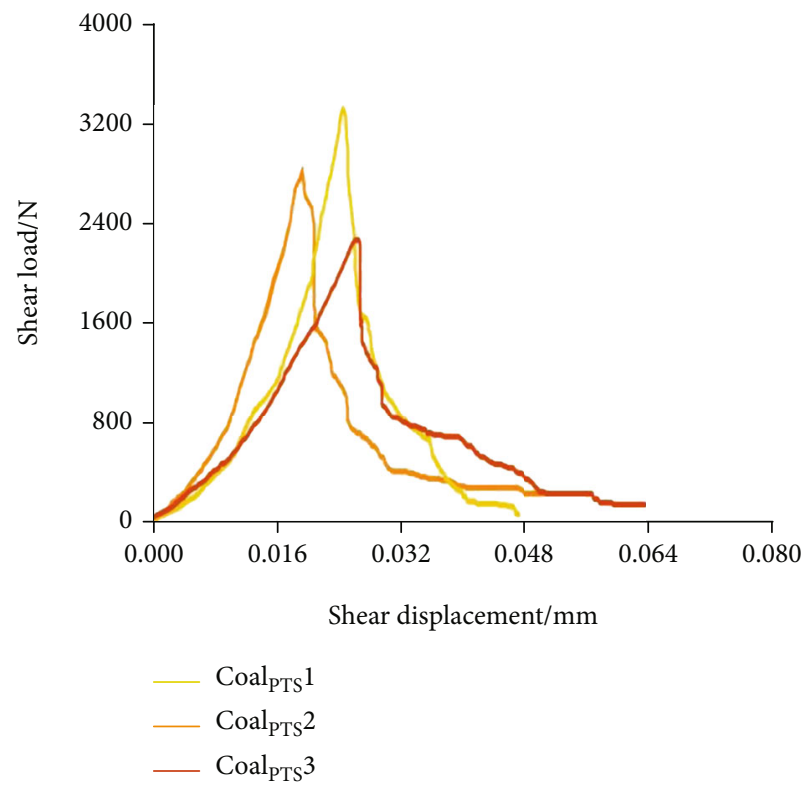

Figure 5: Curves of shear load displacement for specimens of coal PTS. 
the peak shear load to the effective shear area, the shear strength $\left(\tau_{t}\right)$ of coal can be obtained directly. The calculation formula is as follows:

$$
\tau_{t}=\frac{P_{\mathrm{scr}}}{I P \cdot I D \cdot \pi}
$$

where $P_{\text {scr }}$ is the peak shear load. According to the above formula, the shear strength of the coal sample is $2.36 \mathrm{MPa}$.

\section{PPR CZM for Coals}

In the PPR model, the normal and tangential cohesive interactions $\left(T_{\mathrm{n}}, T_{\mathrm{t}}\right)$ are functions of the normal or tangential separation $\left(\Delta_{\mathrm{n}}, \Delta_{\mathrm{t}}\right)$, respectively. It should be indicated that $T_{\mathrm{n}}$ approaches zero when $\Delta_{\mathrm{t}}$ reaches the tangential conjugate final crack opening displacement $\left(\bar{\delta}_{\mathrm{t}}\right)$ or $\Delta_{\mathrm{n}}$ reaches the maximum normal crack opening width $\left(\delta_{n}\right)$. This represents complete normal failure. Similarly, when $\Delta_{\mathrm{t}}$ reaches its maximum displacement of tangential crack opening $\left(\delta_{t}\right)$ or $\Delta_{\mathrm{n}}$ attains the normal conjugate final crack opening width $\left(\bar{\delta}_{\mathrm{n}}\right)$, full tangential failure takes place. The expressions are as follows:

$$
\begin{aligned}
& T_{\mathrm{n}}\left(\delta_{\mathrm{n}}, \Delta_{\mathrm{t}}\right)=0 T_{\mathrm{n}}\left(\Delta_{\mathrm{n}}, \bar{\delta}_{\mathrm{t}}\right)=0, \\
& T_{\mathrm{t}}\left(\bar{\delta}_{\mathrm{n}}, \Delta_{\mathrm{t}}\right)=0 T_{\mathrm{t}}\left(\Delta_{\mathrm{n}}, \delta_{\mathrm{t}}\right)=0 .
\end{aligned}
$$

When $\Delta_{\mathrm{n}}\left(\Delta_{\mathrm{t}}\right)$ reaches the critical opening width $\delta_{\mathrm{nc}}\left(\delta_{\mathrm{tc}}\right)$, the value of $T_{\mathrm{n}}\left(T_{\mathrm{t}}\right)$ is the maximum normal cohesive strength $\left(\sigma_{\max }\right)$. This is shown as follows:

$$
\begin{aligned}
& \left.\frac{\partial T_{\mathrm{n}}}{\partial \Delta_{\mathrm{n}}}\right|_{\Delta_{\mathrm{n}}=\delta_{\mathrm{nc}}}=0 T_{\mathrm{n}}\left(\delta_{\mathrm{nc}}, 0\right)=\sigma_{\max }, \\
& \left.\frac{\partial T_{\mathrm{t}}}{\partial \Delta_{\mathrm{t}}}\right|_{\Delta_{\mathrm{t}}=\delta_{\mathrm{tc}}}=0 T_{\mathrm{t}}\left(0, \delta_{\mathrm{tc}}\right)=\tau_{\max } .
\end{aligned}
$$

The mode I and mode II fracture energy $\left(\Phi_{n}, \Phi_{t}\right)$ can be calculated by the area underneath the cohesive interactions, as follows:

$$
\Phi_{\mathrm{n}}=\int_{0}^{\delta_{\mathrm{n}}} T_{\mathrm{n}}\left(\Delta_{\mathrm{n}}, 0\right) d \Delta_{\mathrm{n}} \Phi_{\mathrm{t}}=\int_{0}^{\delta_{\mathrm{t}}} T_{\mathrm{n}}\left(0, \Delta_{\mathrm{t}}\right) d \Delta_{\mathrm{t}} .
$$

In this study, the mode I and II fracture energies of coal samples were calculated, respectively, by the unit integral area under the load-relative opening displacement curves in Figures 3 and 5 of the above two kinds of tests. The specific shape of the softening response, i.e., the constitutive relationship of the softening process, remarkably affects the crack propagation. Therefore, nondimensional shape parameter indices $(\alpha, \beta)$ are introduced into the PPR model. When the shape parameter indices are equal to 2 , the gradient of the softening process represents a nearly linear relationship. If the shape criteria are lower than 2 , the cohesive interactions have concave softening trends. Conversely, if the shape indi- ces are higher than 2, the gradient of the softening procedure demonstrates a convex shape.

Considering the foregoing macroscopic fracture criteria and boundary conditions, the potential energy function can then be mathematically expressed in the form below:

$$
\begin{aligned}
\Psi\left(\Delta_{\mathrm{n}}, \Delta_{\mathrm{t}}\right)= & \min \left(\phi_{\mathrm{n}}, \phi_{\mathrm{t}}\right) \\
& +\left[\Gamma_{\mathrm{n}}\left(1-\frac{\Delta_{\mathrm{n}}}{\delta_{\mathrm{n}}}\right)^{\alpha}\left(\frac{m}{\alpha}+\frac{\Delta_{\mathrm{n}}}{\delta_{\mathrm{n}}}\right)^{m}+\left\langle\phi_{\mathrm{n}}-\phi_{\mathrm{t}}\right\rangle\right] \\
& \times\left[\Gamma_{\mathrm{t}}\left(1-\frac{\left|\Delta_{\mathrm{t}}\right|}{\delta_{\mathrm{t}}}\right)^{\beta}\left(\frac{n}{\beta}+\frac{\left|\Delta_{\mathrm{t}}\right|}{\delta_{\mathrm{t}}}\right)^{n}+\left\langle\phi_{\mathrm{t}}-\phi_{\mathrm{n}}\right\rangle\right] .
\end{aligned}
$$

The cohesive interactions $T_{\mathrm{n}}$ and $T_{\mathrm{t}}$ are obtained by taking the first derivative of the PPR model along with the normal vector and tangential vector, respectively, as follows:

$$
\begin{aligned}
T_{\mathrm{n}}\left(\Delta_{\mathrm{n}}, \Delta_{\mathrm{t}}\right)= & \frac{\Gamma_{\mathrm{n}}}{\delta_{\mathrm{n}}}\left[m\left(1-\frac{\Delta_{\mathrm{n}}}{\delta_{\mathrm{n}}}\right)^{\alpha}\left(\frac{m}{\alpha}+\frac{\Delta_{\mathrm{n}}}{\delta_{\mathrm{n}}}\right)^{m-1}\right. \\
& \left.-\alpha\left(1-\frac{\Delta_{\mathrm{n}}}{\delta_{\mathrm{n}}}\right)^{\alpha-1}\left(\frac{m}{\alpha}+\frac{\Delta_{\mathrm{n}}}{\delta_{\mathrm{n}}}\right)^{m}\right] \\
& \times\left[\Gamma_{\mathrm{t}}\left(1-\frac{\left|\Delta_{\mathrm{t}}\right|}{\delta_{\mathrm{t}}}\right)^{\beta}\left(\frac{n}{\beta}+\frac{\left|\Delta_{\mathrm{t}}\right|}{\delta_{\mathrm{t}}}\right)^{n}+\left\langle\phi_{\mathrm{t}}-\phi_{\mathrm{n}}\right\rangle\right],
\end{aligned}
$$

$$
\begin{aligned}
T_{\mathrm{t}}\left(\Delta_{\mathrm{n}}, \Delta_{\mathrm{t}}\right)= & \frac{\Gamma_{\mathrm{t}}}{\delta_{\mathrm{t}}}\left[n\left(1-\frac{\Delta_{\mathrm{n}}}{\delta_{\mathrm{n}}}\right)^{\beta}\left(\frac{n}{\beta}+\frac{\left|\Delta_{\mathrm{t}}\right|}{\delta_{\mathrm{t}}}\right)^{n-1}\right. \\
& \left.-\beta\left(1-\frac{\left|\Delta_{\mathrm{t}}\right|}{\delta_{\mathrm{t}}}\right)^{\beta-1}\left(\frac{n}{\beta}+\frac{\left|\Delta_{\mathrm{t}}\right|}{\delta_{\mathrm{t}}}\right)^{n}\right] \\
& \times\left[\Gamma_{\mathrm{n}}\left(1-\frac{\Delta_{\mathrm{n}}}{\delta_{\mathrm{n}}}\right)^{\alpha}\left(\frac{m}{\alpha}+\frac{\Delta_{\mathrm{n}}}{\delta_{\mathrm{n}}}\right)^{m}+\left\langle\phi_{\mathrm{n}}-\phi_{\mathrm{t}}\right\rangle\right] \frac{\Delta_{\mathrm{t}}}{\left|\Delta_{\mathrm{t}}\right|},
\end{aligned}
$$

where $\langle\cdot\rangle$ is the Macaulay bracket function, whose calculation is as follows:

$$
\langle x\rangle= \begin{cases}0 & (x<0), \\ x & (x \geq 0),\end{cases}
$$

where $m$ and $n$ are the nondimensional exponents, which are determined by the shape parameter indices $(\alpha, \beta)$ and the boundary conditions of the critical separations (Equations (4) and (5)). $m$ and $n$ are determined by

$$
\begin{aligned}
& m=\frac{\alpha(\alpha-1) \lambda_{\mathrm{n}}^{2}}{\left(1-\alpha \lambda^{2}\right)}, \\
& n=\frac{\beta(\beta-1) \lambda_{\mathrm{n}}^{2}}{\left(1-\beta \lambda^{2}\right)},
\end{aligned}
$$


TABLE 1: Fracture criteria of the PPR CZMs for the coal.

\begin{tabular}{ccccccccccc}
\hline$\lambda_{\mathrm{n}}$ & $\lambda_{\mathrm{t}}$ & $\Phi_{\mathrm{n}}\left(\mathrm{J} / \mathrm{m}^{2}\right)$ & $\Phi_{\mathrm{t}}\left(\mathrm{J} / \mathrm{m}^{2}\right)$ & $\Gamma_{\mathrm{n}}$ & $\Gamma_{\mathrm{t}}$ & $\bar{\delta}_{\mathrm{t}}(\mathrm{mm})$ & $\bar{\delta}_{\mathrm{n}}(\mathrm{mm})$ & $\alpha$ & $\beta$ \\
\hline 0.386 & 0.317 & 22.16 & 51.62 & 3.678 & -186.677 & 0.009 & 0.108 & 4.15 & 3.26 \\
\hline
\end{tabular}

where $\lambda_{\mathrm{n}}$ and $\lambda_{\mathrm{t}}$ are the initial slope indicators, i.e., the ratio of the critical crack opening displacement to the maximum crack separation displacement, as determined by

$$
\begin{aligned}
& \lambda_{\mathrm{n}}=\frac{\delta_{\mathrm{nc}}}{\delta_{\mathrm{n}}}, \\
& \lambda_{\mathrm{t}}=\frac{\delta_{\mathrm{tc}}}{\delta_{\mathrm{t}}}
\end{aligned}
$$

where $\Gamma_{\mathrm{n}}$ and $\Gamma_{\mathrm{t}}$ are considered energy constants, which are functions of mode I and II fracture energy $\left(\Phi_{n}, \Phi_{t}\right)$. When $\Phi_{\mathrm{n}}$ is different from $\Phi_{\mathrm{t}}$, the formulas of the energy constants are as follows:

$$
\begin{gathered}
\Gamma_{\mathrm{n}}=\left(-\phi_{\mathrm{n}}\right)^{\left\langle\phi_{\mathrm{n}}-\phi_{\mathrm{t}}\right\rangle /\left(\phi_{\mathrm{n}}-\phi_{\mathrm{t}}\right)}\left(\frac{\alpha}{m}\right)^{m}, \\
\Gamma_{\mathrm{t}}=\left(-\phi_{\mathrm{t}}\right)^{\left\langle\phi_{\mathrm{t}}-\phi_{\mathrm{n}}\right\rangle /\left(\phi_{\mathrm{t}}-\phi_{\mathrm{n}}\right)}\left(\frac{\beta}{n}\right)^{n} .
\end{gathered}
$$

When the values between $\Phi_{\mathrm{n}}$ and $\Phi_{\mathrm{t}}$ are equal, the simplification of energy constants to the following expression is possible:

$$
\begin{aligned}
\Gamma_{\mathrm{n}} & =-\phi_{\mathrm{n}}\left(\frac{\alpha}{m}\right)^{m}, \\
\Gamma_{\mathrm{t}} & =\left(\frac{\beta}{n}\right)^{n} .
\end{aligned}
$$

The unknown parameters of the PPR model needed to establish the PPR CZMs for the coals can be calculated based upon data acquired from the SCB tests and PTS tests. The maximum normal and tangential crack opening width can be determined by considering the boundary conditions of the cohesive strength (4) and (5) and fracture energy (6). The equations are as follows:

$$
\begin{aligned}
& \delta_{\mathrm{n}}=\frac{\Phi_{\mathrm{n}}}{\sigma_{\max }} \alpha \lambda_{\mathrm{n}}\left(1-\lambda_{\mathrm{n}}\right)^{\alpha-1}\left(\frac{\alpha}{m}+1\right)\left(\frac{\alpha}{m} \lambda_{\mathrm{n}}+1\right)^{m-1}, \\
& \delta_{\mathrm{t}}=\frac{\Phi_{\mathrm{t}}}{\tau_{\max }} \beta \lambda_{\mathrm{t}}\left(1-\lambda_{\mathrm{t}}\right)^{\beta-1}\left(\frac{\beta}{n}+1\right)\left(\frac{\beta}{n} \lambda_{\mathrm{t}}+1\right)^{n-1},
\end{aligned}
$$

where the parameters of $\delta_{\mathrm{n}}, \delta_{\mathrm{t}}, \Phi_{\mathrm{n}}, \Phi_{\mathrm{t}}, \sigma_{\max }$, and $\tau_{\max }$ have already been determined. The initial slope indicators $\lambda_{\mathrm{n}}$ and $\lambda_{t}$ can be calculated by Equation (12). The calculation results of the different coals are listed in Table 1. Finally, substituting Equation (11) into Equations (15) and (16), the nondimensional shape parameter indices $(\alpha, \beta)$ could be ascertained by solving the above equations. The values

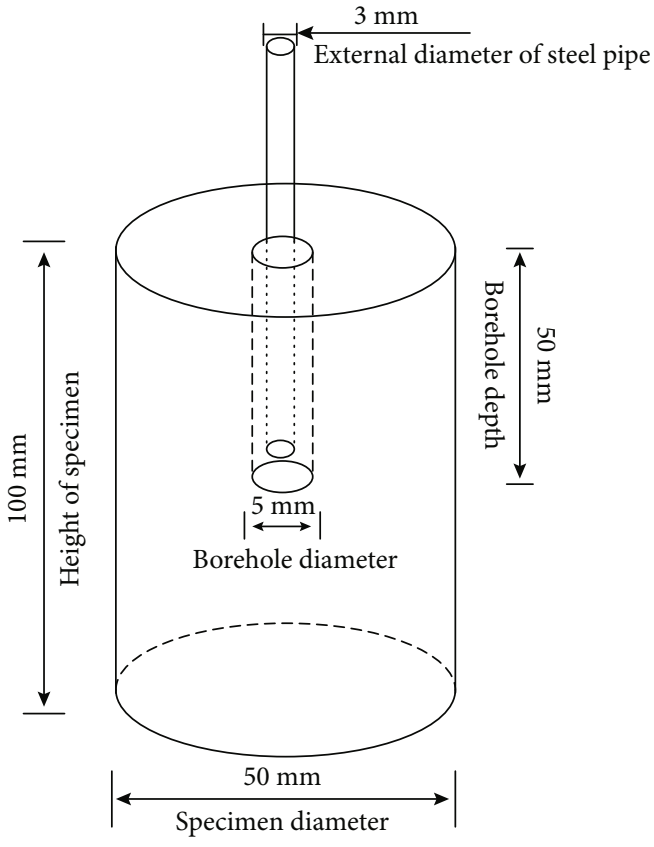

Figure 6: Configuration of the prepared specimens.

of $\alpha(\beta)$ for the three different coals are shown in Table 1 as well.

Based on the experimental results, $\Phi_{\mathrm{n}}$ is different from $\Phi_{\mathrm{t}}$ for the coals; hence, the energy constants $\Gamma_{\mathrm{n}}$ and $\Gamma_{\mathrm{t}}$ were calculated using Equation (12). The results are listed in Table 1. In addition, in order to determine the cohesive interaction region, the last displacements of conjugate crack opening $\bar{\delta}_{\mathrm{t}}$ and $\bar{\delta}_{\mathrm{n}}$ can be calculated by Equations (14) and (15). The cohesive interaction region of mode $\mathrm{I}$ is $(0.108$, 0.009 ), and the cohesive interaction region of mode II is $(0.108,0.055)$. When the normal or tangential separation displacement $\left(\Delta_{\mathrm{n}}, \Delta_{\mathrm{t}}\right)$ exceeded the region, the cohesive stresses of mode I and mode II were set to zero.

\section{Crack Propagation Experiment of Coals for Hydraulic and $\mathrm{ScCO}_{2}$ Fracturing}

4.1. Experimental Preparation and Process. In this section, trimmed samples with a diameter of $50 \mathrm{~mm}$ and a length of $100 \mathrm{~mm}$ were used in the experiment. Figure 6 illustrates the configuration of samples, indicating that there is a central borehole in the upper surface of the specimen. Then, a $3 \mathrm{~mm}$ steel pipe was inserted into the borehole to inject the fluid to simulate the fracturing well. The schematic diagram of the hydraulic and $\mathrm{ScCO}_{2}$ fracturing experimental device is shown in Figure 7. In order to perform the fracturing tests, 


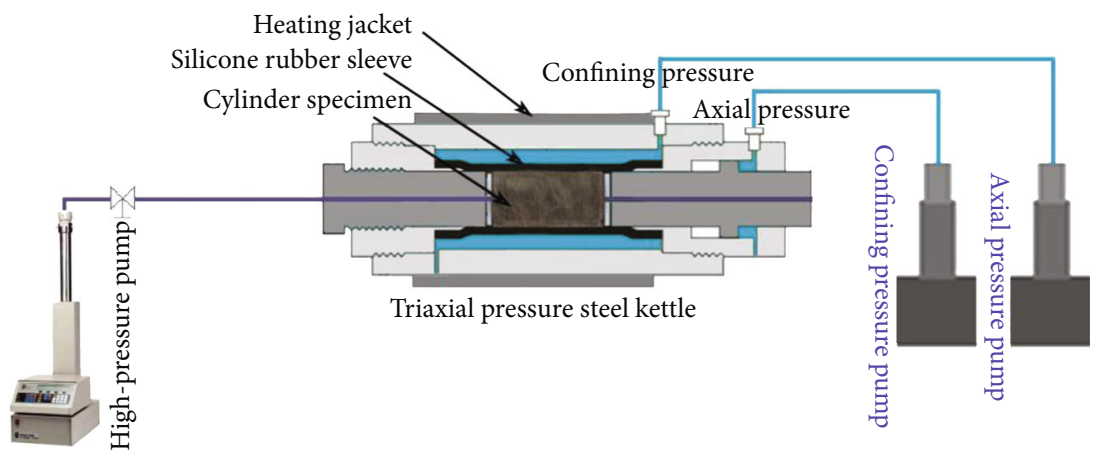

Figure 7: Schematic diagram of the hydraulic fracturing experimental device.

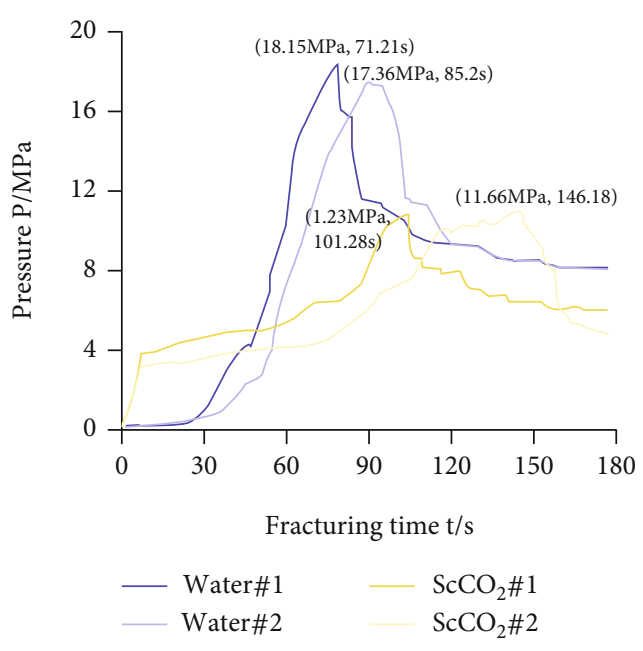

FIGURE 8: Fracturing pressure versus time curves of the coals for hydraulic and $\mathrm{ScCO}_{2}$ fracturing.

the prepared specimens were placed in a pressurized kettle. In order to prevent damage to the specimens, the pressure increment rate was set to $1 \mathrm{MPa} \min ^{-1}$. Meanwhile, $\sigma_{a}$ and $\sigma_{c}$ were set to $10 \mathrm{MPa}$ and $8 \mathrm{MPa}$, respectively. In addition, the temperature of the triaxial pressure kettle was set at $40^{\circ} \mathrm{C}$ and maintained for 3 hours prior to the fracturing test to ensure that the coal sample was fully heated, and the injection flow of the fracturing fluid was set to $20 \mathrm{~mL} \mathrm{~min}^{-1}$. When $\mathrm{ScCO}_{2}$ fracturing is performed, the steel injection pipe was heated to $40^{\circ} \mathrm{C}$ in advance so that the temperature of carbon dioxide is above its critical temperature $\left(31.1^{\circ} \mathrm{C}\right)$. Sample breakdown was identified to have occurred once the fracturing fluid pressure reduces suddenly and simultaneously; the confining pressure increases abruptly.

4.2. Hydraulic and $\mathrm{ScCO}_{2}$ Fracturing Experimental Results. Two samples were run for each experimental condition. Figure 8 shows the four fluid pressure-time curves of coal specimens by the two kinds of fluid fracturing. The fracturing process of all coal specimens can be divided into three stages. The first stage consists of fluid pressure rising. Fracturing fluid is continuously injected into the fracture specimen by a high-pressure pump to resist the strength of the specimen under confining pressure. At the beginning of this stage, the growth rate of the fluid pressure in each coal specimen is very low, especially for $\mathrm{ScCO}_{2}$ fracturing, because it takes time to fill the anhydrite section of the coal specimen after the fracturing fluid injection. In addition, fracturing fluid injection into the coal body immerses and infiltrates the specimen. In this early stage, the slow increase in fluid pressure becomes significant for $\mathrm{ScCO}_{2}$ fracturing; this is attributed to the relatively developed fracture structure in the center hole of the coal body, and the infiltration effect of $\mathrm{ScCO}_{2}$ is noticeable than water. The second stage consists of crack initiations. When the injected fluid pressure reaches a specific critical value, the critical condition for the crack propagation of the coal specimen is reached, and the coal specimen ruptures. The critical pressure is called the crack initiation pressure of fracturing, and the critical fracturing time it takes to reach the crack initiation pressure is called the crack initiation time. The two kinds of fluid fracturing results of the coal specimens are shown in Table 2. The average crack initiation pressure of coal specimens for hydraulic fracturing is $17.76 \mathrm{MPa}$, about 1.59 times that driven by $\mathrm{ScCO}_{2}$ fracturing. The third stage is the pressure drop stage; when fracturing occurs in the coal sample, the water pressure accordingly decreases. For hydraulic fracturing in coals, the fluid pressure obviously decreases after fracturing. And there is a significant fluctuation in the fluid pressure after $\mathrm{ScCO}_{2}$ fracturing. This is because the crack in the coal sample does not completely penetrate the sample. Due to the surrounding rock and axial pressure, the crack closes once again in the coals, and the continuously injected $\mathrm{ScCO}_{2}$ will drive crack propagation in the specimen repeatedly until the specimen is completely broken.

Figure 9 shows the final crack propagation morphology in the cylindrical coal specimens. The coal specimen eventually formed a macrocrack under the hydraulic drive, which penetrated through the whole cylindrical specimen. Yet, there was no crack penetrating the whole fracture specimen and several widely distributed secondary cracks in the fractured coal specimens by $\mathrm{ScCO}_{2}$. This is because water has greater viscosity and density, which is easy to produce tensile failure in coal specimens, and eventually forms a single penetrating crack. On the other hand, because of the large diffusion coefficient and strong permeability of $\mathrm{ScCO}_{2}$, the influence range in the coal is large, so it is easy to form a 
TABLE 2: Hydraulic and $\mathrm{ScCO}_{2}$ fracturing test results of the coal specimens.

\begin{tabular}{lcccccc}
\hline Sample number & Fracturing fluid & $\sigma_{a}(\mathrm{MPa})$ & $\sigma_{c}(\mathrm{MPa})$ & \multicolumn{2}{c}{$\begin{array}{c}\text { Initiation pressure (MPa) } \\
\text { Test value }\end{array}$} & \multicolumn{2}{c}{$\begin{array}{c}\text { Initiation time } t(\mathrm{~s}) \\
\text { Average value }\end{array}$} & $\begin{array}{c}\text { Test value } \\
\text { Average value }\end{array}$ \\
\hline Water\#1 & Water & 10 & 8 & 18.15 & 17.76 & 71.21 \\
Water\#2 & Water & 10 & 8 & 17.36 & 11.26 & 78.24 \\
$\mathrm{ScCO}_{2} \# 1$ & $\mathrm{ScCO}_{2}$ & 10 & 8 & 11.23 & 101.28 \\
$\mathrm{ScCO}_{2} \# 2$ & $\mathrm{ScCO}_{2}$ & 10 & 8 & 11.66 & 146.18 & 123.73 \\
\hline
\end{tabular}

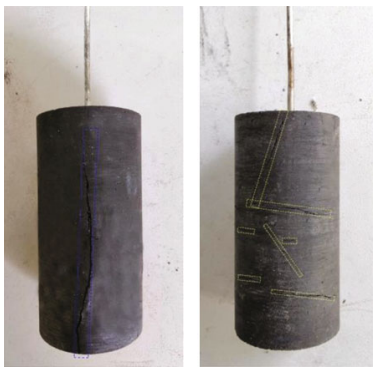

FIGURE 9: Crack propagation paths for the coal samples fractured by (1) water and (2) $\mathrm{ScCO}_{2}$.

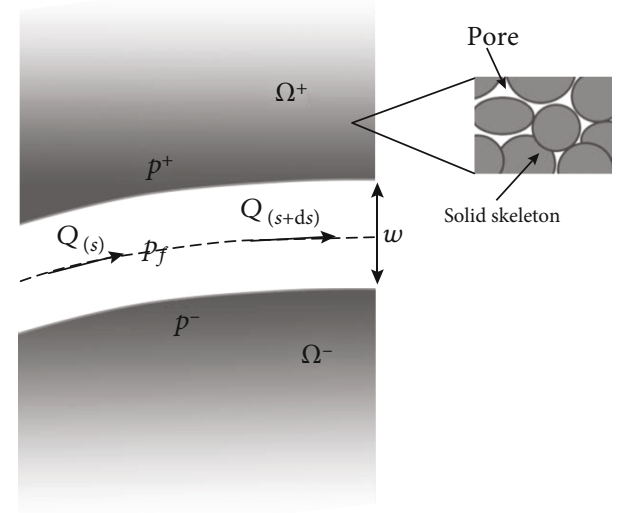

FIgURe 10: Physical model of fluid fracturing in coals.

wide range of tensile and shear mixed-mode cracks in the coal specimens.

\section{Numerical Simulation of Fracturing in Coals Based on the PPR Model}

5.1. Governing Equations. Hydraulic and $\mathrm{ScCO}_{2}$ fracturing of coal is a complex, multifield coupling process. Compared with the multiphysical coupling problems in rock mechanic engineering, this crack propagation process in a solid is coupled with fracturing, causing it to be more challenging to model and calculate. The physical model of the fracturing process in coals is shown in Figure 10. $\Omega$ represents the entire range of the hydraulic fracturing models, and the fracture width $w$ is located in the center of the model. The two sides of the fracture consist of coal materials. The coal is a porous medium, containing the solid skeleton and pores.

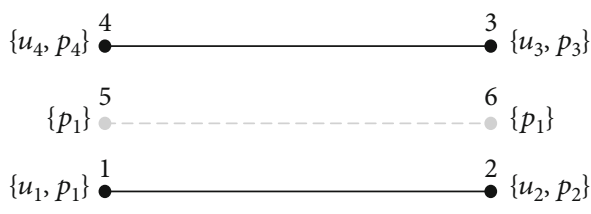

FIGURE 11: The pore pressure cohesive element.

In the fracture, $Q$ represents the flow rate of the injected fracturing fluid. Some of the fluid will be filtered along the upper and lower crack surfaces and permeate into the coal through the pores. The pressure generated by the injected fracturing fluid in the fracture is defined as $P_{f}$. When the fluid pressure reaches a critical value, the crack in the coal body will expand.

The coal fracturing numerical simulation was performed through the pore pressure cohesive element. Figure 11 shows the pore pressure cohesive element with the fluid pressure node. When the cohesive element is affected by the external force, the upper node $(1,2)$ and the lower node $(3,4)$ in the element are relatively displaced, which damages the cohesive element. Once the critical condition is reached, the cohesive element is destroyed, fracturing the material. During this process, the normal cohesion of the element also changes with the change in normal opening displacement. Also, the tangential cohesion of the element changes with the change of the tangential displacement. The relationship between the two cohesive forces and the displacement of the element nodes is the constitutive relationship of the cohesive crack. As shown in Figure 11, the pore pressure cohesive element consists of adding a group of pore pressure injection nodes $(5,6)$ in the center of the original cohesive element. The injected fluid pressure is already included in the cell calculation model through this pressure node, and the injected fluid pressure causes the relative displacement on the lower and upper surfaces of the cohesive element, resulting in continuous damage to the cohesive element until it is destroyed. This represents crack growth in the fracturing model. In this multifield coupled numerical model, there are four governing equations, including the deformation equation of porous media in coal, the pore seepage equation of porous media in coal, the fracture flow equation in coal, and the constitutive equation of a cohesive crack in coal.

(1) In this model, if the pores in the coal body are filled with a single liquid (water or $\mathrm{ScCO}_{2}$ ), the deformation of the coal body includes deformation of the 
solid skeleton and deformation of the liquid in the pores. According to the momentum conservation equation, the following formula can be obtained:

$$
\nabla \sigma+\rho b=0
$$

where $\sigma$ is the total stress tensor of the porous media, $b$ is the physical force of the porous medium, and $\rho$ is the density of the coal. The coal density has the following formula:

$$
\rho=(1-n) \rho_{\mathrm{s}}+n \rho_{\mathrm{f}}
$$

where $n$ is the porosity of the coal, $\rho_{\mathrm{s}}$ is the solid skeleton density of coal, and $\rho_{\mathrm{f}}$ is the fluid density in the coal pore. According to the Biot porous elasticity theory [44] and the Terzaghi theory [45], the effective stress in coal can be calculated as follows:

$$
\sigma_{i j}^{\prime}=\sigma_{i j}+\alpha p_{w} \delta_{i j}
$$

where $\delta_{i j}$ is the Kronecker-delta symbol, $p_{w}$ is the pore pressure in the coal, and $\alpha$ is the Biot coefficient. The Biot coefficient is defined as follows:

$$
\alpha=1-\frac{K_{b}}{K_{S}}
$$

where $K_{b}$ is the total volume modulus of the porous coal media and $K_{S}$ is the modulus of the solid skeleton in the coal. For the incompressible solid material, $K_{s}=\infty, \quad \alpha=1$. If the Biot coefficient $(\alpha)$ is equal to 0 , the porous media material will degenerate into a dense linear elastic solid material.

Based on the hypothesis of small deformation, the formula is as follows:

$$
\varepsilon_{i j}=\frac{1}{2}\left(u_{i, j}+u_{j, i}\right)
$$

where $\varepsilon_{i, j}$ is the strain tensor, $u_{i}$ is the displacement vector, and $u_{i, j}$ and $u_{j, i}$ are the partial derivatives of displacement. The constitutive relation between the stress and strain of coal can be expressed as follows:

$$
\sigma_{i j}=D_{i j k l} \varepsilon_{k l} \text {, }
$$

where $D_{i j k l}$ is the elastic tensor of coal.

(2) Pore seepage in the coal body should satisfy the following mass conservation equation:

$$
\frac{1}{Q} p_{w}+\alpha \nabla \dot{u}+\nabla \dot{w}_{w}=0
$$

where $1 / Q$ is the compressibility coefficient of the fluid, $p_{w}$ is the pore pressure of coal, and $\dot{w}_{w}$ is the velocity vector of
Darcy flow. The compressibility coefficient $1 / Q$ can be calculated as follows:

$$
\frac{1}{Q}=\frac{\alpha-n}{K_{s}}+\frac{n}{K_{w}}
$$

where $n$ is the porosity of coal and $K_{w}$ is the modulus of the fluid. In Equation (16), the flow rate and fluid pressure gradient in porous media satisfy Darcy's law, and the expression is as follows:

$$
\dot{w}_{w}=k_{w}\left(-\nabla p_{w}+\rho_{w}(b-\ddot{u})\right)
$$

where $\rho_{w}$ is the density of the fracturing fluid and $k_{w}$ is the permeability coefficient of the fracturing fluid, which can be calculated as

$$
k_{w}=\frac{k}{\mu_{w}},
$$

where $\mu_{w}$ is the viscosity of the fracturing fluid and $k$ is the permeation matrix.

The effect of the inertia term of the fracturing fluid and the roughness of the crack surface are not considered. The fracturing fluid in the fracture itself can be divided into the tangential flow and normal flow. According to the mass conservation theorem, the fluid in the fracture should satisfy the following equation:

$$
\frac{1}{W_{f}} \dot{p}_{f}+\alpha_{f} \dot{w}+\frac{\partial q}{\partial s}+\left(q_{t}+q_{b}\right)=Q(t) \delta(x, y),
$$

where $1 / W_{f}$ is the compressibility of the fluid in the fracture, $p_{f}$ is the fluid pressure of the fracturing fluid in the fracture, $w$ is the crack opening, $s$ is the coordinate of the tangential direction along the fracture surface, $q_{t}$ is the flow rate of the fracturing fluid filtered from the upper surface of the fracture into the porous media, $q_{b}$ is the flow rate of the fracturing fluid infiltrating from the lower surface of the fracture into the porous media, $Q(t)$ is the flow rate of the source term of the fluid, and $\delta(x, y)$ is the Dirac-delta function. If the fracturing fluid is incompressible, the first fluid compression term in the above equation can be ignored.

The tangential flow and pressure gradient of the fracture fluid in the fracture satisfy the cubic seepage model [46, 47]. They can be related by the following expression:

$$
q=-\frac{w^{3}}{12 \mu_{f}} \frac{\partial p_{f}}{\partial s}
$$

where $\mu_{f}$ is the viscosity of the fracture fluid. Some of the fracturing fluid in the fracture infiltrates into the coal body through the fractures. In this numerical model, the fluid flow rate is related to the gradient between the pore pressure in 
the coal and the pressure of the fracturing fluid in the fracture, calculated as follows:

$$
\begin{aligned}
& q_{t}=k_{t}\left(p_{f}-p_{t}\right), \\
& q_{b}=k_{b}\left(p_{f}-p_{b}\right),
\end{aligned}
$$

where $p_{t}$ and $p_{b}$ are the pore pressures on the upper and lower surfaces of the crack, respectively, and $k_{t}$ and $k_{b}$ are the fluid filtration coefficients on the upper and lower surfaces of the crack, respectively. The equation of the tangential fluid flow in the fracture and the equation of normal fluid flow are taken into the mass conservation equation and expressed as follows:

$$
\dot{w}-\nabla \cdot\left(\frac{w^{3}}{12 \mu_{w}} \nabla p_{f}\right)+c_{1}\left(p_{f}+p_{t}\right)+c_{b}\left(p_{f}-p_{b}\right)=Q(t) \delta(x, y) .
$$

(3)The constitutive relationship of the cohesive element in the numerical simulation of hydraulic fracturing is derived from the mixed-mode I/II PPR potential energy function. In Section 3, the fracture parameter values in the PPR CZMs of the coal were determined through the SCB tests and the PTS tests. The constitutive equations of mixed-mode I/II for a cohesive crack of the different coals were established. The normal and tangential cohesions were obtained by taking the first derivative of the normal displacement and tangential displacement, respectively, by the PPR potential function, and the stiffness matrix of the cohesive element is as follows:

$$
D\left(\Delta_{\mathrm{n}}, \Delta_{\mathrm{t}}\right)=\left[\begin{array}{cc}
D_{\mathrm{nn}} & D_{\mathrm{nt}} \\
D_{\mathrm{tn}} & D_{\mathrm{tt}}
\end{array}\right]=\left[\begin{array}{cc}
\frac{\partial^{2} \Psi}{\partial \Delta_{\mathrm{n}}{ }^{2}} & \frac{\partial^{2} \Psi}{\partial \Delta_{\mathrm{n}} \partial \Delta_{\mathrm{t}}} \\
\frac{\partial^{2} \Psi}{\partial \Delta_{\mathrm{t}} \partial \Delta_{\mathrm{n}}} & \frac{\partial^{2} \Psi}{\partial \Delta_{\mathrm{t}}{ }^{2}}
\end{array}\right] .
$$

The stiffness components of the PPR cohesive constitutive equation are as follows:

$$
\begin{aligned}
D_{\mathrm{nn}}= & \frac{\Gamma_{\mathrm{n}}}{\delta_{\mathrm{n}}{ }^{2}}\left[\left(m^{2}-m\right)\left(1-\frac{\Delta_{\mathrm{n}}}{\delta_{\mathrm{n}}}\right)^{\alpha}\left(\frac{m}{\alpha}+\frac{\Delta_{\mathrm{n}}}{\delta_{\mathrm{n}}}\right)^{m-2}\right. \\
& +\left(\alpha^{2}-\alpha\right)\left(1-\frac{\Delta_{\mathrm{n}}}{\delta_{\mathrm{n}}}\right)^{\alpha-2}\left(\frac{m}{\alpha}+\frac{\Delta_{\mathrm{n}}}{\delta_{\mathrm{n}}}\right)^{m} \\
& \left.-2 \alpha m\left(1-\frac{\Delta_{\mathrm{n}}}{\delta_{\mathrm{n}}}\right)^{\alpha-1}\left(\frac{m}{\alpha}+\frac{\Delta_{\mathrm{n}}}{\delta_{\mathrm{n}}}\right)^{m-1}\right] \\
& \cdot\left[\Gamma_{\mathrm{t}}\left(1-\frac{\Delta_{\mathrm{t}}}{\delta_{\mathrm{t}}}\right)^{\beta}\left(\frac{n}{\beta}+\frac{\Delta_{\mathrm{t}}}{\delta_{\mathrm{t}}}\right)^{n}+\left\langle\phi_{\mathrm{t}}-\phi_{\mathrm{n}}\right\rangle\right],
\end{aligned}
$$

$$
\begin{aligned}
D_{\mathrm{tt}}= & \frac{\Gamma_{\mathrm{t}}}{\delta_{\mathrm{t}}^{2}}\left[\left(n^{2}-n\right)\left(1-\frac{\Delta_{\mathrm{t}}}{\delta_{\mathrm{t}}}\right)^{\beta}\left(\frac{n}{\beta}+\frac{\Delta_{\mathrm{t}}}{\delta_{\mathrm{t}}}\right)^{n-2}\right. \\
& +\left(\beta^{2}-\beta\right)\left(1-\frac{\Delta_{\mathrm{t}}}{\delta_{\mathrm{t}}}\right)^{\beta-2}\left(\frac{n}{\beta}+\frac{\Delta_{\mathrm{t}}}{\delta_{\mathrm{t}}}\right)^{n} \\
& \left.-2 \beta n\left(1-\frac{\Delta_{\mathrm{t}}}{\delta_{\mathrm{t}}}\right)^{\beta-1}\left(\frac{n}{\beta}+\frac{\Delta_{\mathrm{t}}}{\delta_{\mathrm{t}}}\right)^{n-1}\right] \\
& \cdot\left[\Gamma_{\mathrm{n}}\left(1-\frac{\Delta_{\mathrm{n}}}{\delta_{\mathrm{n}}}\right)^{\alpha}\left(\frac{m}{\alpha}+\frac{\Delta_{\mathrm{n}}}{\delta_{\mathrm{n}}}\right)^{m}+\left\langle\phi_{\mathrm{n}}-\phi_{\mathrm{t}}\right\rangle\right], \\
D_{\mathrm{nt}}= & \frac{\Gamma_{\mathrm{n}} \Gamma_{\mathrm{t}}}{\delta_{\mathrm{n}} \delta_{\mathrm{t}}}\left[m\left(1-\frac{\Delta_{\mathrm{n}}}{\delta_{\mathrm{n}}}\right)^{\alpha}\left(\frac{m}{\alpha}+\frac{\Delta_{\mathrm{n}}}{\delta_{\mathrm{n}}}\right)^{m-1}\right. \\
& \left.-\alpha\left(1-\frac{\Delta_{\mathrm{n}}}{\delta_{\mathrm{n}}}\right)^{\alpha-1}\left(\frac{m}{\alpha}+\frac{\Delta_{\mathrm{n}}}{\delta_{\mathrm{n}}}\right)^{m}\right] \\
& -\left[n\left(1-\frac{\Delta_{\mathrm{t}}}{\delta_{\mathrm{t}}}\right)^{\beta}\left(\frac{n}{\beta}+\frac{\Delta_{\mathrm{t}}}{\delta_{\mathrm{t}}}\right)^{n-1}-\beta\left(1-\frac{\Delta_{\mathrm{t}}}{\delta_{\mathrm{t}}}\right)^{\beta-1}\left(\frac{n}{\beta}+\frac{\Delta_{\mathrm{t}}}{\delta_{\mathrm{t}}}\right)^{n}\right] .
\end{aligned}
$$

5.2. Numerical Models of Hydraulic Fracturing for the Coals. In order to compare the experimental fracturing results of the coals, the coal material parameters and boundary conditions of the coals in the fracturing numerical models were set to be the same as those in the experiments. Figure 12 shows the boundary conditions on the coal fracturing numerical geometric model with a size of $50 \mathrm{~mm} \times 50 \mathrm{~mm}$, as well as the meshing conditions for a section of the model. In the fracturing numerical model, the coal materials were characterized by triangular solid elements, and the pore pressure cohesive elements were inserted between the triangular solid elements to simulate multiple crack propagation driven by hydraulic or $\mathrm{ScCO}_{2}$ fracturing. To avoid the influence of the overall stiffness of the model after a large number of cohesive elements were inserted between the solid elements (see Figure 12), the corresponding upper and lower nodes in the cohesive element and their intermediate fluid pressure nodes were defined at the same position in the local coordinate system. This numerical simulation method is called the zero-thickness element method [48]. And the fluid injection point was set at the center of the numerical model, and the fluid injection rate was set to $20 \mathrm{~mL} / \mathrm{min}$. The involved numerical simulation parameters are given in Table 3 , and the PPR model parameters of the three types of coals are listed in Table 1 for the numerical simulation for the hydraulic and $\mathrm{ScCO}_{2}$ fracturing of the coal specimens. In addition, the contrast numerical simulation of the fracturing in coals was also carried out in which the constitutive relationship of the pore pressure cohesive elements was represented by the common linear elastic fracture mechanics (LEFM).

Figure 13 shows the numerical simulation results of hydraulic and $\mathrm{ScCO}_{2}$ fracturing of the coals. The fracture initiation pressure of the coal with water or $\mathrm{ScCO}_{2}$ is 18.45 $\mathrm{MPa}$ and $11.75 \mathrm{MPa}$, respectively. These numerical simulation outcomes are in agreement with the experiment's achievements. Compared with the established PPR model, the numerical simulation results of fracturing and $\mathrm{ScCO}_{2}$ 


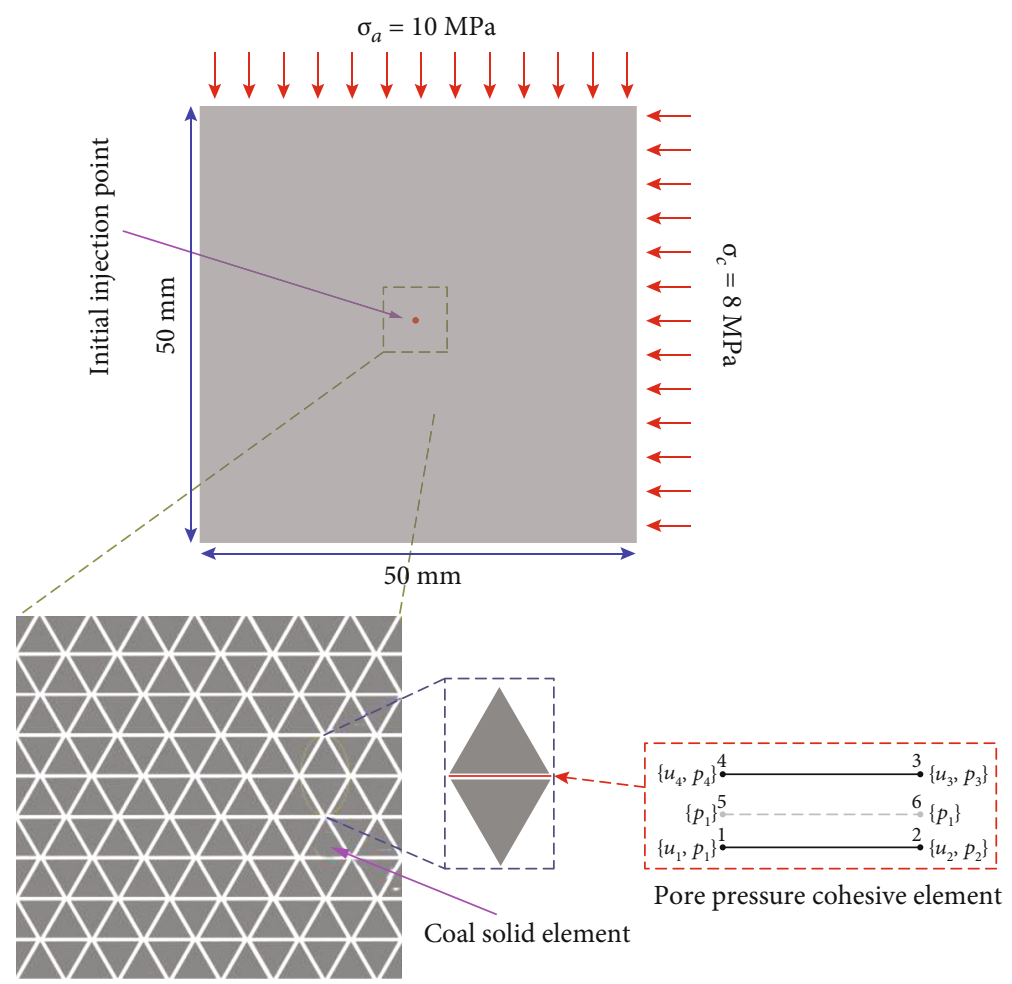

FIgURE 12: The numerical model for fracturing in coals.

TABLE 3: Numerical simulation parameters of the different fluid fracturing in coals.

\begin{tabular}{lcc}
\hline Fracturing fluid & Water & $\mathrm{ScCO}_{2}$ \\
\hline Permeability $K\left(\mathrm{~m}^{2}\right)$ & $0.2 \times 10^{-15}$ & $0.6 \times 10^{-14}$ \\
Initial pore pressure $P_{0}(\mathrm{MPa})$ & 0.1 & 0.1 \\
Injection velocity $Q(\mathrm{~mL} / \mathrm{min})$ & 20 & 20 \\
Dynamic viscosity coefficient of fracturing fluid $(\mathrm{Pa} \cdot \mathrm{s})$ & $0.79 \times 10^{-3}$ & $0.31 \times 10^{-3}$ \\
Fracturing fluid density $\rho\left(\mathrm{kg} / \mathrm{m}^{3}\right)$ & 1000 & 770 \\
Filtration coefficient $C_{\mathrm{t}}\left(\mathrm{m}^{3} / \mathrm{MPa} \mathrm{s}\right)$ & $1.0 \times 10^{-6}$ & $3.5 \times 10^{-6}$ \\
\hline
\end{tabular}

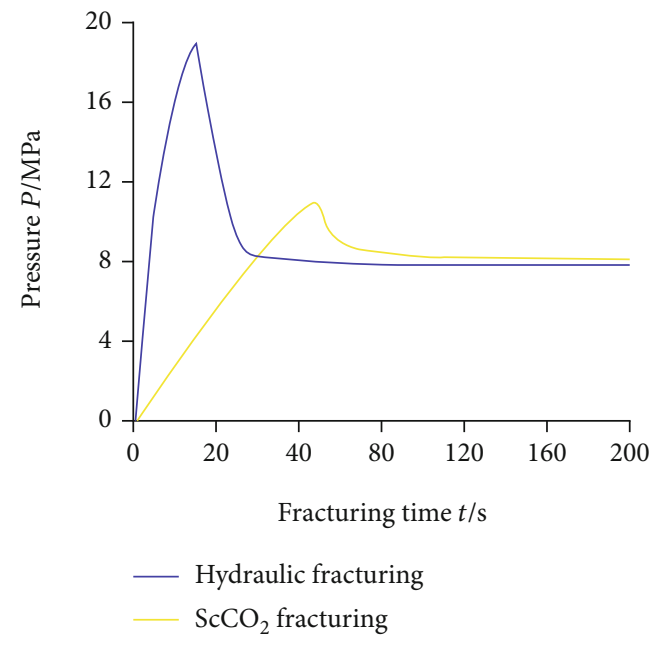

FIgURE 13: Fracturing pressure over time for hydraulic and $\mathrm{ScCO}_{2}$ fracturing numerical simulation of coals based on the PPR model.

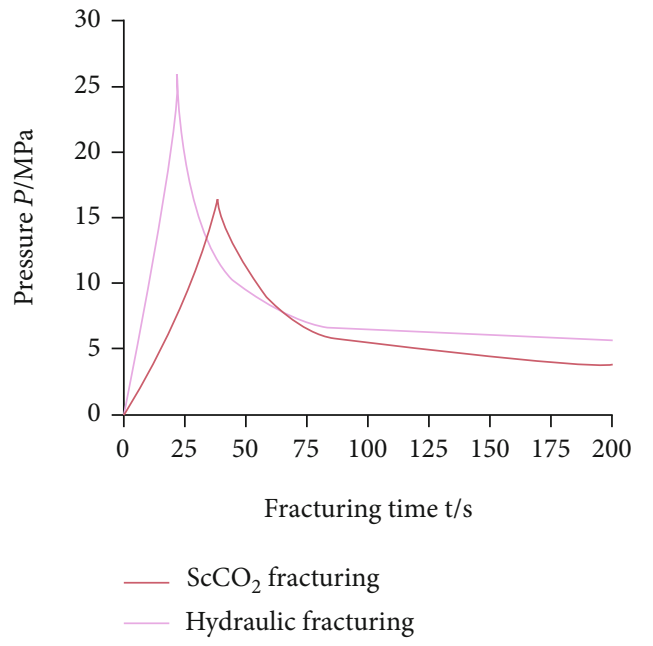

FIGURE 14: Fracturing pressure over time for hydraulic and $\mathrm{ScCO}_{2}$ fracturing numerical simulation of coals based on LFEM. 


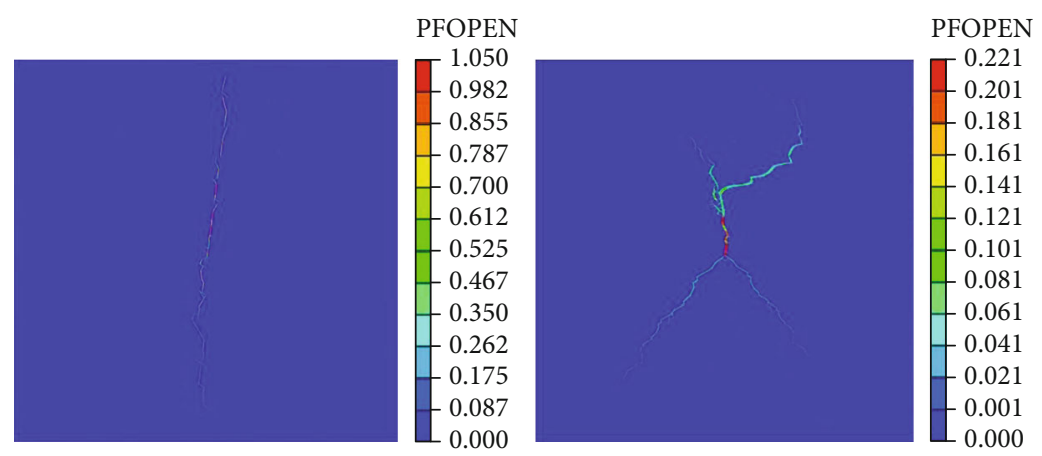

FIGURE 15: Crack propagation numerical simulation of coals caused by (1) hydraulic fracturing and (2) $\mathrm{ScCO}_{2}$ fracturing.

in the coals are shown in Figure 14 based on the LFEM, and there are obvious deviations between the simulation results and the test results. Figure 15 shows the simulation results of crack growth for hydraulic and $\mathrm{ScCO}_{2}$ fracturing in the coal samples. The crack induced by hydraulic fracturing expands along the direction of the maximum principal stress, and at the same time, secondary crack propagation occurs near the main crack. And the multiple crack propagation appears in the coal model with $\mathrm{ScCO}_{2}$ fracturing. This is also consistent with the experimental results of crack propagation in coal specimens caused by hydraulic and $\mathrm{ScCO}_{2}$ fracturing. Therefore, this demonstrates that the established PPR CZMs can accurately describe crack propagation behavior in varying coal types for hydraulic and $\mathrm{ScCO}_{2}$ fracturing.

\section{Conclusion}

In this research, the mixed-mode I/II PPR cohesive zone model (CZM) of coals was determined using PTS and SCB tests. The constitutive relationships of the established PPR CZMs were introduced into the pore pressure cohesive elements to simulate crack growth in coals caused by hydraulic and $\mathrm{ScCO}_{2}$ fracturing. In addition, hydraulic and $\mathrm{ScCO}_{2}$ fracturing experiments on the coal specimens were performed, and the numerical simulation outcomes were compared with the corresponding experimental results. The following conclusions can be drawn:

(1) Several key fracture parameters, including the maximum normal open displacement $\left(\delta_{n}\right)$, the maximum tangential open displacement $\left(\delta_{t}\right)$, mode I fracture energy $\left(\Phi_{\mathrm{n}}\right)$, and mode II fracture energy $\left(\Phi_{t}\right)$, were obtained through SCB tests and PTS tests. According to the experimental results, there are visible nonlinear damage processes in the stage of postpeak loading, and the coal specimens show obvious characteristics of ductile fracture under mode I and II loading. In addition, the mode II fracture energy of coal type II is $51.62 \mathrm{~J} / \mathrm{m}^{2}$, which is considerably greater compared with fracture energy of mode I for coal $\left(22.16 \mathrm{~J} / \mathrm{m}^{2}\right)$; this shows that the mode II crack propagation in coals will use remarkable energy in coals
(2) In the hydraulic and $\mathrm{ScCO}_{2}$ fracturing experiments of coals, the crack initiation pressure of coal specimens for hydraulic fracturing is $17.76 \mathrm{MPa}$, about 1.59 times that driven by $\mathrm{ScCO}_{2}$ fracturing. And the crack initiation time of coal with $\mathrm{ScCO}_{2}$ fracturing is $123.73 \mathrm{~s}$, which is 1.58 times that for hydraulic fracturing. A macrocrack eventually formed in the coal specimen due to the hydraulic drive, which penetrated through the entire specimen, whereas there was no crack penetrating the whole fracture specimen and several widely distributed secondary cracks in the fractured coal specimens by $\mathrm{ScCO}_{2}$. This is because water has greater viscosity and density, which is easy to produce tensile failure in coal specimens, and eventually forms a single penetrating crack. On the other hand, because of the large diffusion coefficient and strong permeability of $\mathrm{ScCO}_{2}$, the influence range in the coal is large, so it is easy to form a wide range of tensile and shear mixed-mode cracks in the coal specimens

(3) The PPR CZMs of the coal were established using PTS and SCB tests for analyzing the mixed-mode I/II crack propagation. Zero-thickness pore pressure cohesive elements were used to simulate multicrack propagation in coals caused by hydraulic and $\mathrm{ScCO}_{2}$ fracturing. The constitutive relationships of the established PPR CZM were introduced into the cohesive elements. Overall, the numerical simulation results are consistent with the hydraulic and $\mathrm{ScCO}_{2}$ fracturing experimental results for the coal specimens. This indicates that the established PPR CZMs can accurately represent crack propagation behavior in coals caused by hydraulic and $\mathrm{ScCO}_{2}$ fracturing

\section{Data Availability}

The underlying data and figures can be found in the manuscript.

\section{Conflicts of Interest}

The authors declare that they have no conflicts of interest. 


\section{Acknowledgments}

The authors thank the financial supports from the National Natural Science Foundation of China (NSFC) under Grant No. 52004203 and the Outstanding Youth Science Fund of Xi'an University of Science and Technology (2021).

\section{References}

[1] C. Fan, S. Li, D. Elsworth, J. Han, and Z. Yang, "Experimental investigation on dynamic strength and energy dissipation characteristics of gas outburst-prone coal," Energy Science \& Engineering, vol. 8, no. 4, pp. 1015-1028, 2020.

[2] J. Zhang, L. Si, J. Chen, M. Kizil, and Z. Chen, "Stimulation techniques of coalbed methane reservoirs," Geofluids, vol. 2020, 23 pages, 2020.

[3] C. Fan, D. Elsworth, S. Li, L. Zhou, Z. Yang, and Y. Song, "Thermo-hydro-mechanical-chemical couplings controlling $\mathrm{CH}_{4}$ production and $\mathrm{CO}_{2}$ sequestration in enhanced coalbed methane recovery," Energy, vol. 173, pp. 1054-1077, 2019.

[4] X. Wang, Q. Hu, and Q. Li, "Investigation of the stress evolution under the effect of hydraulic fracturing in the application of coalbed methane recovery," Fuel, vol. 300, p. 120930, 2021.

[5] S. Chen, D. Tang, S. Tao, P. Liu, and J. P. Mathews, "Implications of the in situ stress distribution for coalbed methane zonation and hydraulic fracturing in multiple seams, western Guizhou, China," Journal of Petroleum Science and Engineering, vol. 204, p. 108755, 2021.

[6] Y. Meng, D. Tangm, H. Xu, Y. Li, and L. Gao, "Coalbed methane produced water in China: status and environmental issues," Environmental Science and Pollution Research, vol. 21, no. 11, pp. 6964-6974, 2014.

[7] R. Middleton, H. Viswanathan, R. Currier, and R. Gupta, “ $\mathrm{CO}_{2}$ as a fracturing fluid: potential for commercial- scale shale gas production and $\mathrm{CO}_{2}$ sequestration," Energy Procedia, vol. 63, pp. 7780-7784, 2014.

[8] H. Yan, J. Zhang, N. Zhou, B. Li, and Y. Wang, "Crack initiation pressure prediction for $\mathrm{SC}-\mathrm{CO}_{2}$ fracturing by integrated meta-heuristics and machine learning algorithms," Engineering Fracture Mechanics, vol. 249, p. 107750, 2021.

[9] H. Yan, J. Zhang, B. Li, and C. Zhu, "Crack propagation patterns and factors controlling complex crack network formation in coal bodies during tri-axial supercritical carbon dioxide fracturing," Fuel, vol. 286, p. 119381, 2021.

[10] M. Meng and Z. Qiu, "Experiment study of mechanical properties and microstructures of bituminous coals influenced by supercritical carbon dioxide," Fuel, vol. 219, pp. 223-238, 2018.

[11] T. Ishida, K. Aoyagi, T. Niwa et al., "Acoustic emission monitoring of hydraulic fracturing laboratory experiment with supercritical and liquid $\mathrm{CO}_{2}$," Geophysical Research Letters, vol. 39, no. 16, pp. 1-6, 2012.

[12] X. Zhang, Y. Lu, J. Tang, Z. Zhou, and Y. Liao, "Experimental study on fracture initiation and propagation in shale using supercritical carbon dioxide fracturing," Fuel, vol. 190, pp. 370-378, 2017.

[13] D. Zhou, G. Zhang, Y. Wang, and Y. Xing, "Experimental investigation on fracture propagation modes in supercritical carbon dioxide fracturing using acoustic emission monitoring," International Journal of Rock Mechanics and Mining Sciences, vol. 110, pp. 111-119, 2018.
[14] D. Wu, X. Liu, B. Liang, K. Sun, and X. Xiao, "Experiments on displacing methane in coal by injecting supercritical carbon dioxide," Energy \& Fuels, vol. 32, no. 12, pp. 12766-12771, 2018.

[15] G. R. Irwin, "Analysis of stresses and strains near the end of a crack traversing a plate," J Appl Mech, vol. 24, no. 3, pp. 361364, 1957.

[16] A. A. Griffith, "VI. The phenomena of rupture and flow in solids," Philosophical transactions of the royal society of london. Series A, containing papers of a mathematical or physical character, vol. 221, no. 582-593, pp. 163-198, 1921.

[17] Z. T. Bieniawski, "Mechanism of brittle fracture of rock: part I-theory of the fracture process," Int J Rock Mech Min Sci (1997), vol. 4, no. 4, pp. 395-406, 1967.

[18] Z. T. Bieniawski, "Mechanism of brittle fracture of rock: part II-experimental studies," Int J Rock Mech Min Sci (1997), vol. 4, no. 4, pp. 407-423, 1967.

[19] F. Dai, Y. Xu, T. Zhao, N. W. Xu, and Y. Liu, "Loading-ratedependent progressive fracturing of cracked chevronnotched Brazilian disc specimens in split Hopkinson pressure bar tests," Int J Rock Mech Min Sci (1997), vol. 88, pp. 49-60, 2016.

[20] M. D. Kuruppu, Y. Obara, M. R. Ayatollahi, K. P. Chong, and T. Funatsu, "ISRM-suggested method for determining the mode I static fracture toughness using semi-circular bend specimen," Rock Mechanics and Rock Engineering, vol. 47, no. 1, pp. 267-274, 2014.

[21] G. Feng, Y. Kang, X. Wang, Y. Hu, and X. Li, "Investigation on the failure characteristics and fracture classification of shale under Brazilian test conditions," Rock Mechanics and Rock Engineering, vol. 53, no. 7, pp. 3325-3340, 2020.

[22] C. Yang, J. J. K. Daemen, and J. H. Yin, "Experimental investigation of creep behavior of salt rock," Int J Rock Mech Min Sci (1997), vol. 36, no. 2, pp. 233-242, 1999.

[23] B. Du, H. Bai, and G. Wu, Dynamic Compression Properties and Deterioration of Red-Sandstone Subject to Cyclic WetDry Treatment, Advances in Civil Engineering, 2019.

[24] Z. P. Bažant and M. T. Kazemi, "Determination of fracture energy, process zone longth and brittleness number from size effect, with application to rock and conerete," International Journal of Fracture, vol. 44, no. 2, pp. 111-131, 1990.

[25] B. Nie, X. Liu, L. Yang, J. Meng, and X. Li, "Pore structure characterization of different rank coals using gas adsorption and scanning electron microscopy," Fuel, vol. 158, pp. 908917, 2015.

[26] G. I. Barenblatt, "The mathematical theory of equilibrium cracks in brittle fracture," Advances in Applied Mechanics, vol. 7, no. C, pp. 55-129, 1962.

[27] D. S. Dugdale, "Yielding of steel sheets containing slits," Journal of the Mechanics and Physics of Solids, vol. 8, no. 2, pp. 100-104, 1960.

[28] A. Hillerborg, M. E. Modéeer, and P. E. Petersson, “Analysis of crack formation and crack growth in concrete by means of fracture mechanics and finite elements," Cement and Concrete Research, vol. 6, no. 6, pp. 773-781, 1976.

[29] Z. Chen, A. P. Bunger, X. Zhang, and R. G. Jeffrey, "Cohesive zone finite element-based modeling of hydraulic fractures," Acta Mechanica Solida Sinica, vol. 22, no. 5, pp. 443-452, 2009.

[30] H. Wang, "Numerical modeling of non-planar hydraulic fracture propagation in brittle and ductile rocks using XFEM with 
cohesive zone method," Journal of Petroleum Science and Engineering, vol. 135, pp. 127-140, 2015.

[31] J. Planas and M. Elices, "Asymptotic analysis of a cohesive crack: 2. Influence of the softening curve," International Journal of Fracture, vol. 64, no. 3, pp. 221-237, 1993.

[32] Y. Gong, Y. Hou, L. Zhao, W. Li, J. Zhang, and N. Hu, "A modified mode I cohesive zone model for the delamination growth in DCB laminates with the effect of fiber bridging," International Journal of Mechanical Sciences, vol. 176, p. 105514, 2020.

[33] Z. Bennour, T. Ishida, Y. Nagaya et al., "Crack extension in hydraulic fracturing of shale cores using viscous oil, water, and liquid carbon dioxide," Rock Mechanics and Rock Engineering, vol. 48, no. 4, pp. 1463-1473, 2015.

[34] J. R. K. Zipf and Z. T. Bieniawski, "Mixed-mode fracture toughness testing of coal," International Journal of Rock Mechanics and Mining Science \& Geomechanics Abstracts, vol. 27, no. 6, pp. 479-493, 1990.

[35] Y. Zhao, S. Gong, X. Hao, Y. Peng, and Y. Jiang, "Effects of loading rate and bedding on the dynamic fracture toughness of coal: laboratory experiments," Engineering Fracture Mechanics, vol. 178, pp. 375-391, 2017.

[36] M. J. Lee, T. M. Cho, W. S. Kim, B. C. Lee, and J. J. Lee, “Determination of cohesive parameters for a mixed-mode cohesive zone model," International Journal of Adhesion and Adhesives, vol. 30, no. 5, pp. 322-328, 2010.

[37] R. D. S. G. Campilho, M. F. S. F. De Moura, A. M. G. Pinto, J. J. L. Morais, and J. J. M. S. Domingues, "Modelling the tensile fracture behaviour of CFRP scarf repairs," Composites Part B: Engineering, vol. 40, no. 2, pp. 149-157, 2009.

[38] S. H. Song, G. H. Paulino, and W. G. Buttlar, "A bilinear cohesive zone model tailored for fracture of asphalt concrete considering viscoelastic bulk material," Engineering Fracture Mechanics, vol. 73, no. 18, pp. 2829-2848, 2006.

[39] K. Park and G. H. Paulino, "Cohesive zone models: a critical review of traction-separation relationships across fracture surfaces," Applied Mechanics Reviews, vol. 64, no. 6, pp. 60-80, 2011.

[40] K. Park, G. H. Paulino, and J. R. Roesler, "A unified potentialbased cohesive model of mixed-mode fracture," Journal of the Mechanics and Physics of Solids, vol. 57, no. 6, pp. 891-908, 2009.

[41] A. Needleman, "A continuum model for void nucleation by inclusion debonding," Journal of Applied Mechanics, vol. 54, no. 3, pp. 525-531, 1987.

[42] X. P. Xu and A. Needleman, "Void nucleation by inclusion debonding in a crystal matrix," Modelling and Simulation in Materials Science and Engineering, vol. 1, no. 2, pp. 111-132, 1993.

[43] T. Backers, O. Stephansson, and E. Rybacki, "Rock fracture toughness testing in mode II-punch-through shear test," Journal of Rock Mechanics and Mining Sciences, vol. 39, no. 6, pp. 755-769, 2002.

[44] M. A. Biot, "General theory of three-dimensional consolidation," Journal of Applied Physics, vol. 12, no. 2, pp. 155-164, 1941.

[45] K. Terzaghi, Theoretical Soil Mechanics, Chapman and Hall, Limited, London, 1951.

[46] Y. Chen, A. P. S. Selvadurai, and W. Liang, "Computational modelling of groundwater inflow during a longwall coal mining advance: a case study from the Shanxi province, China,"
Rock Mechanics and Rock Engineering, vol. 52, pp. 917-934, 2019.

[47] Y. Chen, A. P. S. Selvadurai, and Z. Zhao, "Modeling of flow characteristics in $3 \mathrm{D}$ rough rock fracture with geometry changes under confining stresses," Computers and Geotechnics, vol. 130, p. 103910, 2021.

[48] V. P. Nguyen, "An open source program to generate zerothickness cohesive interface elements," Advances in Engineering Software, vol. 74, pp. 27-39, 2014. 